\title{
«CRITICAL LEGAL STUDIES» Y EL COMUNITARISMO
}

\section{Introducción: ¿qué es «Critical Legal Studies»?}

e temo que para abordar las relaciones entre el movimiento norteamericano «Critical Legal Studies» (en adelante, CLS) y el comunitarismo, y en concreto, la cuestión de qué actitud adoptaría CLS ante el comunitarismo $\mathrm{y}$, en su caso, qué es lo que CLS podría aportar al debate entre comunitaristas y liberales, es obligado hacer antes una presentación de CLS. Digo que «me temo» tener que presentar a CLS porque sintetizar en pocas líneas, de manera comprensible, lo que es este movimiento (no digamos ya una breve definición) resulta prácticamente imposible. CLS es inefable debido a su heterogeneidad, su interdisciplinariedad, su eclecticismo teórico descarado, su carácter literalmente paradójico... Para expresar esto, a mí me gusta desgranar una cita de uno de sus miembros, James Boyle, que recoge tan sólo una pequeña muestra de la colección de paradojas en que consiste CLS ${ }^{1}$ :

-«Visto desde fuera, CLS aparece como una extraña mezcla de realismo jurídico, Nueva Izquierda y crítica literaria». (De momento, ya tenemos algo).

-«[CLS] Oscila -añade Boyle- entre filosofía europea salvajemente esotérica y esmeradas descripciones de la fina textura de interacciones sociales cotidianas». Lo de «filosofía europea esotérica»se refiere a las tradiciones filosóficas que suelen predominar en CLS, y que están en las antípodas de la filosofía analítica anglosajona: ellos tienden más bien hacia la tradición anti o post ilustrada: Hegel, el joven Marx, Nietzsche, Heidegger, la fenomenología, el

${ }^{1}$ Boyle, James, «The Politics of Reason: Critical Legal Theory and Local Social Thought», 133 University of Pennsylvania Law Review 685 (1985), en pág. 688. 
pragmatismo americano, el existencialismo, el estructuralismo y el postestructuralismo, el psicoanálisis, Foucault, Derrida... Pero también incluyen en su menú la teoría social clásica (Marx, Weber, Durkhem), y si se tercia, elementos de autores y teorías «racionalistas». Y es que el debate interno a CLS entre los llamados «racionalistas» e «irracionalistas» ha marcado y sigue marcando su historia. En cuanto a lo de «esmeradas descripciones de la fina textura de interacciones sociales cotidianas», eso seguramente alude a su rechazo a la "gran teoría» y su adopción de lo que ellos denominan «teoría local»: la búsqueda de explicaciones «científicas» globales del mundo social, basadas en poderosas estructuras que se suceden según tendencias determinantes, traiciona para ellos la idea de la complejidad y la contingencia social, y congela la posibilidad de imaginar órdenes alternativos; su eclecticismo teórico renuncia, pues, a compatibilizar tan rico bagaje construyendo una teoría-síntesis coherente, y opta en cambio por una especie de bricolaje intelectual adaptando los más diversos elementos para su uso en prácticas teóricas a pequeña escala. -Volvamos a la cita de Boyle: «[CLS] Es de izquierdas, y sin embargo es profundamente crítico con el marxismo». Ya tenemos algo más: su componente marxista -que sólo es uno más- es el del neomarxismo crítico occidental que desarrolló la «crítica marxista al marxismo»: Lukács, Gramsci o la Escuela de Frankfurt. Más que el marxismo, es el espíritu de la Nueva Izquierda americana de los años sesenta lo que marca sus señas de «identidad colectiva».

-«Es un enemigo descarado de la jerarquía, y sin embargo es a menudo accesible solamente para quienes se encuentran en la cúspide de la pirámide académica». Esto alude a que la crítica marxista tradicional en términos de clase es sustituida en CLS por la idea más vacía de «jerarquía», que incluye además la crítica a las «jerarquías ilegítimas» de género, raza, orientación sexual, etc. Pero muchos «CLSers» a su vez se han consolidado en lo más alto de la jerarquía académica, en facultades de élite (empezando por Harvard), donde han desarrollado un polémico «activismo» orientado a la transformación de la enseñanza del Derecho, que es uno de sus temas favoritos.

-«Generalmente -añade Boyle- se critica a CLS por ser demasiado teórico, y sin embargo sus protagonistas parecen creer que inspira un tipo inmediato y concreto de acción política, tanto dentro como fuera de las facultades de Derecho». Ésta es para mí una de las claves para empezar a entender a CLS: CLS es ante todo un movimiento político-académico, una «plataforma política» para la izquierda en las facultades de Derecho norteamericanas, y ésta es la razón principal que explica la cohesión de un movimiento intelectualmente tan heterogéneo. Ocurre que su proyecto político-académico es insepa- 
rable de su proyecto intelectual. Partiendo de la difuminación de la distinción entre teoría y práctica, entre conocimiento y política, y de una epistemología antipositivista (al estilo de la Escuela de Frankfurt, por ejemplo), la crítica ideoló gica del Derecho desarrollada por CLS consiste en examinar cómo la conciencia jurídica (creada por los juristas, pero extendida a todos) contribuye a la creación de una conciencia o «representación» del mundo social (tesis general de la «construcción social» de la realidad, y particular del carácter «constitutivo» más que causal del Derecho en la sociedad).

Según ellos esa visión juridificada del mundo se presenta como verdadera y necesaria, por lo que CLS aspira a mostrar cómo puede ser transformada mediante la crítica interna y detallada de las incoherencias del pensamiento jurídico plasmadas en miles de normas e instituciones jurídicas concretas, descongelando así la «falsa necesidad» de esa visión y abriendo el camino a la imaginación y propuesta de mundos alternativos. Esta tesis ha suscitado la crítica de «idealismo» que se ha dirigido contra CLS desde una izquierda más tradicional (o más «materialista», más «científica» o «positivista»), ya que parece sugerir que podemos cambiar el mundo con sólo pensarlo (representárnoslo) de otra manera. Pero el debate idealismo/materialismo, acerca de en qué sentido y hasta qué punto las ideas constituyen y pueden transformar el mundo «real», queda lejos de lo que aquí nos ocupa. En todo caso, quizá ahora se entienda mejor el final de la cita de Boyle:

-«Por último, CLS es antiformalista, y sin embargo toma al Derecho positivo más en serio que cualquier otra escuela contemporánea de pensamiento jurídico». De momento, me interesa detenerme especialmente en este punto. Tras estas pinceladas dispersas sobre qué es CLS no sé si se desprende cuál es su «leit motiv»: el de la indeterminación, la contingencia, la plasticidad del mundo y la posibilidad de transformarlo. Las críticas «locales» de CLS se han dirigido contra una gran variedad de discursos: contra el formalismo jurídico, la sociología behaviorista y la ingeniería social, el «policy analysis», la teoría liberal del Estado, el determinismo marxista, el análisis económico del Derecho, la enseñanza del Derecho... pero siempre subyace el rechazo a las pretensiones de naturalidad, de neutralidad, racionalidad, cientificidad y apoliticismo que ellos encuentran en esos discursos, y que en último término los convertiría en «discursos de poder», porque ese riguroso racionalismo llevaría el germen de una visión sólida y estable del estado de cosas dominante que lo protegería al desanimar los intentos dirigidos a subvertirlo; se trataría de negar la autoridad e inmutabilidad que la apelación a la neutralidad confiere a la práctica en cuestión, y de mostrar que las cosas pueden ser distintas. 
Ahora bien: de entre todos los discursos criticados, la crítica de CLS ha partido de (y ha vuelto siempre a) el Derecho, CLS es un movimiento de juristas, de dogmáticos del Derecho positivo en sus diversas ramas; no son iusfilósofos, y mucho menos filósofos a secas. Cierto es que hacen constantes «incursiones» (por cierto, muchas veces con la ligereza de un diletantismo muy mal parapetado, aunque otras veces con verdadero conocimiento de causa) en la teoría del Derecho, en la filosofía política y moral e incluso en la filosofía pura (y también en la economía, la sociología, la crítica literaria, la psicología, etc.). Pero su objetivo central ha sido la crítica interna de la razón jurídica, en sus aspectos más detallados y (supuestamente) técnicos de Derecho de contratos, Derecho laboral, administrativo, constitucional, etc.; precisamente su tendencia a fagocitar esas otras disciplinas tiene por finalidad mostrar, a su luz, la falsa autonomía del Derecho y del razonamiento jurídico respecto de la discusión sustantiva de carácter moral y político. Insisto en esto porque resulta fundamental para entender su relación con el comunitarismo. El análisis de dicha relación debe partir pues de otro relato de CLS: el que se inicia en su crítica a las contradicciones internas del Derecho.

\section{La crítica de la CLS a las contradicciones del derecho}

Sintetizando muchísimo, la versión «clásica» de la tesis de CLS sobre la indeterminación del Derecho sería más o menos ésta: CLS recupera y reproduce los conocidos argumentos de los realistas contra la ilusión de certeza, predecibilidad y aplicabilidad mecánica del Derecho, enfatizando en cambio la indeterminación del lenguaje jurídico y la discrecionalidad del intérprete; en particular, CLS destaca las inconsistencias entre reglas y doctrinas que, como decía Walter Whecler Cook, «tienen el hábito de salir a cazar por parejas» ${ }^{2}$. Pero CLS extiende este último argumento realista, mostrando cómo los conflictos no sólo surgen en el sistema formal de reglas, sino también en el de objetivos sociales («policies») y principios valorativos en los que aquéllas se inspiran, y a los que, según el programa constructivo de los propios realistas, desarrollado por la jurisprudencia posterior a ellos, había que acudir para recuperar la certeza. El enfoque funcional de la jurisprudencia finalista y del «policy analysis», que apela a supuestos consensos sociales no cuestionados y a una especie de racionalidad instrumental inmanente al

${ }^{2}$ Cook, Walter W., «Review of The Paradoxes of Legal Science by Benjamin Cardozo», 38 Yale Law Journal 406 (1929). 
ordenamiento jurídico, seguiría ocultando la verdadera dimensión política y conflictiva del Derecho. La «Legal Process School» representaría una síntesis entre formalismo clásico y realismo que reconoce el carácter sustantivo de las decisiones jurídicas, pero sigue eludiendo esa dimensión conflictiva: se evita la necesidad de tomar partido al remitir la legitimidad del Derecho hacia aquella decisión que haya sido tomada por el órgano institucionalmente competente según el procedimiento establecido (el principio de la «institutional settlement» de Hart y Sacks), con lo que la normatividad del Derecho radicaría en el proceso formal y objetivo y no en su sustancia controvertible. La jurisprudencia de principios de tipo dworkiniano ya no oculta en el proceso la controvertida dimensión político-moral del Derecho, pero cree posible resolver racionalmente sus conflictos sustantivos acudiendo a la ponderación entre principios o a su reconstrucción en una teoría integradora coherente. Para CLS, todos estos intentos únicamente sirven para empujar hacia otro nivel el punto por el cual se introduce la indeterminación y la necesidad de genuina elección. La tesis es que filosófica, moral y políticamente el Derecho contemporáneo está simultáneamente comprometido con polos opuestos de presupuestos e ideales irreconciliables, y los conflictos en los materiales jurídico-positivos no son sino manifestaciones de esas contradicciones situadas en niveles mucho más profundos. En último término, lo que subyace son las contradicciones del «pensamiento liberal», entendido éste en un sentido amplísimo, a veces prácticamente coextensivo con la visión del hombre y del mundo y con la forma de racionalidad que llamamos «moderna» o «ilustrada». No puedo desarrollar aquí el análisis de estas dicotomías, pero enumeraré algunas: Roberto Unger habla, entre otras, de la «antinomia de la razón y el deseo» (y de la moralidad de la razón, deontológica, frente a la moralidad del deseo, consecuencialista) y de la «antinomia de las reglas y los valores» (ola tensión entre justicia formal y justicia sustantiva) ; $^{3}$; Duncan Kennedy destaca la tensión entre individualismo y altruismo ${ }^{4}$; Mark Kelman añade la del subjetivismo/objetivismo de los valores y la del intencionalismo/ determinismo acerca de la acción humana ${ }^{5} \ldots$

En realidad, sólo una mínima parte de la literatura CLS se detiene a analizar en detalle, en un discurso filosófico y no jurídico, esas

${ }^{3}$ Unger, Roberto Mangabeira, Knowledge and Politics, The Free Press, New York, 1975, 2. ed., 1984, esp. caps. 1 y 2.

${ }^{4}$ Kennedy, Duncan, «Form and Substance in Private Law Adjudication», 89 Harvard Law Review 1685 (1976).

${ }^{5}$ Kelman, Mark, A Guide to Critical Legal Studies, Harvard University Press, Cambridge, MA, 1987, esp. caps. 2 y 3. 
supuestas contradicciones del liberalismo: más bien se afirman, siguiendo la estela marcada por Roberto Unger en la parte crítica de su obra Conocimiento y política. A CLS sobre todo le interesa rastrear esos polos en sus manifestaciones jurídicas (tanto o más que en el Derecho objetivo, en la argumentación jurídica estándar). En particular, por lo que aquí nos ocupa, CLS no ha desarrollado explícitamente la tensión entre lo que podríamos etiquetar como «universalismo individualista», por un lado, y comunitarismo, por el otro. Pero yo creo que no sería arriesgado interpretarles extendiendo su análisis para incluir también esta dicotomía (que de todos modos parece estar presente, de forma más o menos implícita, en su repertorio de contradicciones) ${ }^{6}$. Como en los demás casos, CLS afirmaría que el pensamiento filosófico-moral moderno se debate también entre esos dos polos, pero sobre todo se detendría a estudiar su plasmación en el discurso jurídico. Intentarían detectar en el Derecho americano la presencia de reglas, doctrinas, principios, instituciones y también teorías o argumentaciones jurídicas de inspiración «comunitarista», que se opondrían a la inspiración liberal más evidente de ese Derecho. Esta investigación seguramente sería interesante, y yo sospecho que, al menos aplicada al Derecho americano, arrojaría un resultado positivo (probablemente encontrarían, p.ej., argumentos más o menos veladamente patrióticos, apelaciones a la «tradición jurídica nacional», regulaciones positivas protectoras de una concepción comunitarista de la familia, las comunidades religiosas, los municipios, corporaciones o gremios profesionales, así como parcelas del discurso jurídico teórico más o menos inspiradas en el comunitarismo como el llamado «republicanismo cívico»...).

El análisis CLS de las contradicciones «liberales» en el Derecho se completa -acabo de insinuarlo- con una idea fundamental: ocurre que el pensamiento y la práctica jurídica dominante ocultan esas contradicciones al «privilegiar» ideológicamente uno solo de los términos de cada dicotomía (los polos privilegiados serían los «conservadores», según muchos CLSers, aunque para otros, por ejemplo Duncan Kennedy, la conexión entre unos u otros polos, por un lado, y programas políticos progresistas o conservadores, por el otro, es mucho más contingente). Por ejemplo, como señala Kelman, las normas jurídicas asociadas a los ideales del individualismo, la realizabilidad formal de las reglas, la subjetividad de los valores y la libre

${ }^{6}$ Gerald Frug, en «The City as a Legal Concept» (93 Harvard Law Review 1057, en pág. 1075), alude a la dicotomía entre «el desarrollo del yo y la necesidad de relaciones comunales», aunque en su posterior análisis y reivindicación del poder de los municipios como cuerpos intermedios se centra sobre todo en la crítica a la distinción liberal entre lo público y lo privado. 
voluntad se tratan como paradigmáticos y en principio aplicables, mientras que las normas asociadas a los ideales del altruismo, la sensibilidad hacia el contexto, la objetividad de los valores y el determinismo en la acción humana se ven como excepcionales y necesitadas de una especial justificación. (En nuestra dicotomía, añado yo, el polo universalista-individualista sería el privilegiado). Estos «privilegios» permiten cierto grado, a veces elevado, de predecibilidad empírica respecto de las decisiones jurídicas. Pero CLS insiste en la indeterminación justificatoria: las convenciones que estabilizan al Derecho son mucho más frágiles de lo que parece, los polos reprimidos siguen estando ahí, al menos «reconocidos» o proclamados, por lo que un buen jurista podría justificar plausiblemente, apelando a ellos, soluciones no convencionales (algo muy parecido al uso alternativo del Derecho).

Insisto en que es esto lo que de verdad interesa a CLS. Pero a nosotros aquí nos interesa en cambio volver al nivel superior de las contradicciones filosóficas del liberalismo.

\section{CLS y el comunitarismo}

Que yo sepa, no existe literatura en CLS que aborde directamente sus posibles semejanzas o diferencias con el comunitarismo. Yo voy a intentar aquí esbozar una reconstrucción de esas relaciones dividiendo mi exposición en dos grandes apartados: 1) en su vertiente crítica, CLS y el comunitarismo comparten algunos rasgos comunes al enfrentarse al liberalismo. 2) En su dimensión positiva o constructiva, el grueso de CLS rechazaría los esfuerzos del comunitarismo por ofrecer una reconstrucción filosófica normativa alternativa, aunque la vena utópica de CLS contiene a menudo vagas alusiones a un ideal social que puede tener tintes comunitaristas ${ }^{7}$.

${ }^{7}$ Vaya por delante un «descarte» que seguramente tenía que haber mostrado antes. A cualquiera que se plantee la relación entre CLS y el comunitarismo, lo primero que le viene a la mente son las evidentes similitudes entre este último y al menos tres componentes normalmente asociados a CLS: 1) la llamada "Teoría Crítica de la Raza» (Critical Race Theory), y en general el «multiculturalismo» contemporáneo; 2) la «Jurisprudencia Feminista» (mejor dicho, el sector del feminismo jurídico más ligado al llamado «feminismo de la diferencia» al estilo de Carol Gilligan), así como las teorías críticas sobre la orientación sexual: y 3) Roberto Unger. Mucho se ha escrito sobre el «comunitarismo» de quienes, frente al universalismo ilustrado abstracto, totalizador, «eurocéntrico» o «masculino», reivindican el reconocimiento y la promoción de otras «voces diferentes», surgidas de las experiencias peculiares de grupos y culturas marginados o socialmente subordinados; la realidad existencial de vivir como mujer, como negro, como homosexual, etc., configuraría una «identidad» comunitaria, con una visión del mundo, unos valores y hasta 


\section{La vertiente crítica: aproximación entre CLS y el comunitarismo en la crítica al} liberalismo

Situándose en un nivel muy general, Carlos Thiebaut (y creo que cualquiera lo compartiría) introduce su presentación del comunitarismo trazando una línea divisoria entre, por un lado, la reformulación del proyecto moderno y liberal mediante reconstrucciones racionalistas y cognitivistas de la ética y del «punto de vista moral» con una impronta kantiana, que caracterizó a la filosofía moral y política de los setenta (constructivismo, neocontractualismo, éticas dialógicas), y, por otro lado, las críticas que han caracterizado a los ochenta, enfatizando los límites de ese proyecto racionalista e ilustrado: «bien su ineficacia -dice Thiebaut-, bien los supuestos materiales y nor-

una forma de pensar diferentes -y en muchos casos celebrados como superiores- que estarían impugnando las categorías dominantes de pensamiento y de valoración tradicionalmente construidos desde el paradigma del «varón blanco». Para acotar este trabajo he decidido centrarme en el CLS «clásico», el de sus orígenes y su apogeo a mediados de los años 80 , y dejar de lado los dos primeros conjuntos de corrientes, cuyo estudio me llevaría demasiado lejos dada su afinidad con muchas ideas comunitaristas. A estos efectos, he preferido distinguir lo que podríamos llamar CLS «en sentido estricto» de estas otras corrientes, que sólo parcialmente se solapan con él, y cuya conexión con el «núcleo duro» de las primeras generaciones de CLS puede verse más bien como una relación de colaboración entre movimientos relativamente autónomos aunque muchas veces aliados (aunque reconozco que, en los últimos años, la «intersección» entre CLS y estos otros grupos se ha reforzado notablemente, hasta el punto de que hoy ya no está claro si es CLS quien los ha incorporado en su seno o más bien ha sido absorbido por ellos).

Roberto Unger, el más -o quizá el único- «comunitarista» asociado a CLS, es un caso aparte. En mi opinión, y a pesar de su decisiva influencia en el origen de este movimiento, Unger no es en realidad un CLS, por más que ahí siga encasillado por muchos observadores externos. La parte crítica de su célebre Knowlege and Politics inspiró claramente los ataques de CLS contra el liberalismo, y a ella aludiré más adelante: pero el resto de su obra «constructiva» representa una serie de sucesivos esfuerzos por elaborar una "gran teoría» propia, original, que prácticamente nadie en CLS ha compartido. La alternativa de Unger, al menos en sus orígenes, tiene muchos rasgos comunitaristas (en realidad, su ideal de una comunidad humanista e integrada que supere la dicotomía entre el individuo y la sociedad y en la que al modo aristotélico la naturaleza humana alcance su plena realización, es el de una comunidad universal, un «reino de fines comunes» donde florezca la «simpatía» como sucedáneo social del amor; pero la propuesta para aproximarse a esa utopía -que él reconoce inalcanzable- es la formación de una «comunidad de comunidades» particulares, a las que él llama «grupos orgánicos», donde tiende a desaparecer la oposición entre lo público y lo privado sin aniquilar por ello la individualidad). Ciertamente, hay en CLS frecuentes alusiones -no desarrolladas teóricamente- a un ideal de emancipación humana mediante la consecución de una comunidad universal libre, solidaria y participativa; pero, desde luego, la construcción teórica de Unger no puede en absoluto tomarse como representativa de CLS, y por ello no me detendré en ella. 
mativos que subyacen a todo procedimentalismo (y que, frente a su autosupuesta neutralidad, evidenciarían su carácter necesariamente partidario), bien algunas de sus inconsistencias internas $\rangle^{8}$. El comunitarismo, evidentemente, estaría en este último lado de esa gran frontera, y, como es fácil adivinar, en este sentido amplísimo CLS sería su compañero de trinchera (incluso esto hay que tomarlo con cautela, ya que en CLS convive gente de ambos bandos; pero parece claro en cuál de ellos se situaría su centro de gravedad). Por supuesto que en esa trinchera malconviven soldados muy distintos. Thiebaut traza aquí una segunda división entre los críticos de la modernidad de filiación neorromántica y hegeliana, por un lado, y los que adoptan formas más clásicas -neoaristotélicas- de búsqueda de una moral sustantiva. Ahora yo veo a CLS (salvo excepciones) más próximo a la inspiración romántica-hegeliana, y en esto se distinguiría de la «querencia aristotélica» del esfuerzo comunitarista por reconstruir una ética normativa sustantiva. Pero, como bien señala Thiebaut, ambas querencias suelen aparecer juntas, y en todo caso comparten muchos rasgos en su crítica al proyecto moderno. Veamos pues algunos de esos rasgos comunes, aunque todavía muy generales, entre la crítica de CLS y la de los comunitaristas. Dividiré mi exposición en lo que me parece que son los dos temas centrales del debate con el liberalismo universalista: la concepción de la personalidad humana y la discusión sobre la solución liberal de las reglas de justicia universales.

1.1. Primera aproximación: teoría de la personalidad.-Una primera aproximación entre CLS y el comunitarismo versaría sobre la cuestión al menos aparentemente descriptiva acerca de la constitución del sujeto moral. Me refiero a la conocida crítica contra el liberalismo porque éste partiría de una visión «atomizada», presocial, apriorística, de los individuos como seres aislados («unencumbered»: «descarnados», «desarraigados»), frente a la cual comunitaristas y CLS opondrían la noción de la «construcción social del sujeto»: éste no puede entenderse sin referencia a las prácticas y relaciones concretas que entabla en el marco social y cultural en el que está inserto, y que lo «constituyen» o definen como persona. Por supuesto que aquí la discusión interesante no radica en la aceptación de la idea trivial de que los hombres somos seres sociales, que cualquier liberal aceptaría, sino más bien en el énfasis y alcance que se le quiera dar a la hora de fundamentar una filosofía ética y/o política: desde el extremo de asentarla desde el «punto de vista moral» del

${ }^{8}$ Thiebaut, Carlos, Los límites de la comunidad, Centro de Estudios Constitucionales, Madrid, 1992, pág. 19. 
sujeto noumenal kantiano abstraído de todo condicionamiento empírico (que atentaría contra la dimensión social o «comunal» de la personalidad), hasta el extremo opuesto de la definición colectiva del bien defendida por el comunitarismo más radical (que atentaría contra la autonomía individual). Pero, volviendo de momento al aspecto descriptivo, CLS compartiría con los comunitaristas el rechazo del individualismo «atomista». Uno puede encontrar muchas citas en las que los CLS, al igual que los comunitaristas, atribuyen al enemigo «liberal», yo creo que injustamente, la posición extrema de «completa libertad»-el adjetivo es de Taylor-, y entonces lo critican porque ignora no sólo nuestra inmersión en prácticas comunes, sino también nuestra propia autopercepción, y porque sería además una posición absolutamente vacía: la libertad «no puede especificar -dice Taylor ningún contenido para nuestra acción fuera de una situación que fija objetivos para nosotros» ${ }^{9}$. A esto mismo apunta Unger cuando dice que «[la "moralidad de la razón”] ni siquiera nos permite buscar», y que si la «moralidad del deseo» (o sea, la utilitarista) «nunca concluye» (porque no da criterios para jerarquizar nuestros deseos), la otra sin embargo «nunca comienza». Si los liberales sostuvieran esa tesis, yo creo que los comunitaristas tendrían razón: la libertad no puede ser valiosa en sí misma, sino «para algo». Ella sola no me dice qué quiero hacer, no me proporciona fines. Ocurre que los liberales no estarían hoy en la posición atomista exagerada, por más que, como señala Kymlicka, algunos liberales la hayan abrazado (Isaiah Berlin se la atribuye a Mill) ${ }^{10}$. Pero volvamos a CLS. ¿Su rechazo del atomismo significa que CLS abraza entonces la visión comunitarista «fuerte» de la personalidad? En muchos casos, eso parece. Jack Balkin, por ejemplo, afirma:

«La teoría social que subyace a CLS está basada en la premisa de la construcción social de los pensamientos, creencias y deseos del sujeto a través de la ideología, así como de reglas sociales. La estructura misma de la percepción, creencia y deseo individual, y por lo tanto los términos de la elección individual, están ya conformados por la cultura y la ideología, incluso antes de que el individuo comience a elegir» ${ }^{11}$.

\section{7.}

${ }^{9}$ Taylor, Charles, Hegel and Modern Society, Cambridge University Press, 1979, en pág.

${ }^{10}$ Véase Kymlicka, Will, Contemporary Political Philosophy, Oxford University Press, 1990, en págs. 209-210.

${ }^{11}$ Balkin, Jack. «Ideology as Constraint», 43 Stanford Law Review 1133(1991), en pág. 1137. 
Pero ya he dicho que el «tema» de CLS es el de la contradicción. Muchos otros «CLSers», empezando por Duncan Kennedy, considerarían la visión de Balkin excesivamente «determinista», y a la vez que rechazan la visión unilateral del individuo atomizado, propia del liberalismo tradicional, reprocharían también a Balkin (y a algunos comunitaristas) una visión de la persona próxima a la imagen de un robot socialmente determinado (el propio Balkin se apresura a reconocerlo, al decir que la suya «difícilmente es una posición de libertad nihilista; de hecho demasiado énfasis en la construcción social del sujeto conduce no al nihilismo sino más bien al determinismo»).

La idea, pues, defendida por lo que yo entiendo como el centro del CLS clásico sería una concepción contradictoria, o mejor, dialéctica, de la personalidad, socialmente construida y a la vez individualmente libre. Curiosamente el propio Balkin, poco después del pasaje que acabo de citar (en el que parecía abrazar la concepción comunitarista del yo), escribe lo siguiente:

«CLS ve la realidad social como una dialéctica entre estructuras sociales y el pensamiento, creencia, deseo y acción individual. El pensamiento, creencia, deseo y acción individual están conformados y construidos por estructuras sociales, las cuales a su vez son el producto del pensamiento, creencia, deseo y acción individual previo. Esta visión dialéctica es ininteligible dentro de la dicotomía de "o lo uno, o lo otro"».

Duncan Kennedy, en la misma línea, ha escrito recientemente:

«Estoy diciendo que uno no puede (no debe) negar la importancia de la afiliación o de la identidad en grupos, en todos los aspectos de la vida. Pero también afirmo que los grupos y las identidades son contingentes y fluidos, que cada persona probablemente va a ser internamente contradictoria más bien que lo mismo hasta el final. Mi visión es que las identidades celebradas tanto en la moderna retórica multicultural como en la retórica tradicionalista del grupo mayoritario han de verse mejor como "posiciones", o "situaciones", dentro de las cuales la gente opera como agentes libres. Desde luego que la libertad es relativa a la posición o situación. Pero la libertad efectivamente significa que algunas veces tenemos que elegir cómo manejar las cosas después de haber tomado en cuenta nuestras identidades. No significa que podemos trascender los límites contextuales y hacer o llegar a ser en la vida cualquier cosa que queramos. Y también podemos elegir 
ser leales con nuestras posiciones de identidad constreñidas, elegir ser tan poco libres como sea posible» ${ }^{12}$.

Así pues, este CLS estaría detectando la posición contradictoria no sólo en sí mismo, sino también en el propio pensamiento liberal contemporáneo, una vez que (afortunadamente) ese liberalismo se ha desmarcado de la visión radicalmente atomista del yo que algunos comunitaristas (y, como he dicho, también algunos CLS) creen ver todavía en el liberalismo. Esta contradicción, como las demás del catálogo que antes he recogido, estaría ligada a la célebre «contradicción fundamental» entre el «yo» $\mathrm{y}$ «los otros» de la que habló Duncan Kennedy. La «contradicción fundamental» hace alusión a «nuestros sentimientos dolorosamente contradictorios acerca del estado actual de las relaciones entre las personas en nuestro mundo social». En su trabajo acerca de los Comentarios sobre las leyes de Inglaterra de Blackstone, Kennedy escribe uno de los pasajes más citados en la literatura de y sobre CLS:

«He aquí una formulación inicial de la contradicción fundamental: la mayoría de los participantes en la cultura jurídica americana creen que el objetivo de la libertad individual es al mismo tiempo dependiente de e incompatible con la acción coactiva colectiva que es necesaria para alcanzarlo. Los otros (familia, amigos, burócratas, tipos culturales, el Estado) son necesarios para constituirnos como personas: ellos nos proporcionan la materia [stuff] de nuestro yo, y nos protegen de forma crucial contra la destrucción. Incluso cuando nos parece que estamos más solos, los demás están con nosotros, incorporados a nosotros mediante procesos lingüísticos, cognitivos y emotivos que son como cuestión simplemente biológica, aspectos colectivos de nuestra individualidad. Además, no siempre estamos solos. A veces tenemos experiencias de fusión con otros, en grupos de dos o incluso de dos millones, y es una experiencia más buena que mala (...). Pero a la vez que nos constituye y nos protege -continúa Kennedy-, el universo de los otros (familia, amistad, burocracia, cultura, Estado) nos amenaza con aniquilarnos y nos impulsa hacia formas de fusión que son claramente más malas que buenas. Innumerables sometimientos, grandes y pequeños abandonos del yo a los otros, son el precio de cuanta libertad experimen-

${ }^{12}$ Kennedy, Duncan, Sexy Dressing, etc. Essays on the Power and Politics of Cultural Identity, Harvard University Press, 1993, pág. viii. 
temos en sociedad. Y es un alto precio. Mediante nuestra existencia como miembros de colectivos, imponemos sobre otros, y se nos imponen a nosotros, estructuras jerárquicas de poder, riqueza, y acceso a la cultura que son ilegítimas, ya estén basadas en el nacimiento en una clase particular o en el accidente de las dotes genéticas. (...) La clave es que la abolición de estas estructuras ilegítimas, la confección de una existencia colectiva inalienada, parece implicar un incremento tan masivo de control colectivo sobre nuestras vidas que ello derrotaría su propósito» ${ }^{13}$.

1.2. Segunda aproximación: crítica a la solución liberal de las reglas universales.-Este tema de la contradicción me da pie para abordar un segundo tipo de similitud entre la crítica CLS y la comunitarista, ahora ya claramente en el terreno de la ética más que en el de la teoría de la personalidad (aunque parece claro que la diferencia entre la «psicología» liberal y la comunitarista está en la raíz de sus discrepancias normativas). La crítica de CLS y la comunitarista a las contradicciones del liberalismo tienen bastante en común, porque muchos CLS se han inspirado en uno de sus fundadores, Roberto Unger, cuyo libro Conocimiento y Política, como dice Thiebaut (cit., pág. 37), precisamente «se encuentra en la base de muchas de las actuales críticas comunitaristas, como la de Michael Sandel».

Para Unger, el dilema del liberalismo es (entre otros) el de la antinomia entre, por un lado, la «moralidad del deseo», que define la bondad como «la consecución de los objetivos hacia los que nos inclinan nuestros apetitos y aversiones», los cuales no pueden ser justificados ni jerarquizados racionalmente; y, por el otro, la «moralidad de la razón», que busca establecer racionalmente estándares universales de la conducta correcta.

«La moralidad del deseo -escribe Unger (cit., pág. 51)- es una ética de fines, preocupada por la satisfacción de deseos particulares. La moralidad de la razón es una ética de reglas, los principios universales que limitan la persecución de cual quiera de nuestros fines. Así, se dice que aquélla proclama la prioridad de lo bueno sobre lo correcto, y ésta la prioridad de lo correcto sobre lo bueno».

La tesis de Unger es que cada uno de estos tipos de moral resulta inadecuado, y necesitaría ser corregido por el otro, pero en el marco de la psicología liberal no es posible tal síntesis:

${ }^{13}$ Kennedy, Duncan, «The Structure of BIackstone’s Commentaries», 28 Buffalo Law Review 205 (1979), en págs. 211-212. 
«Para establecer la posibilidad de un orden entre nuestros deseos, tenemos que apelar a la razón. Pero, dentro de los límites de la psicología liberal, la razón no puede evaluar nada. Para dar contenido a los principios formales que la razón establece, uno debe abandonar la postura de neutralidad entre los deseos del individuo, y entre los deseos de distintos individuos. Y, sin embargo, era precisamente para evitar la necesidad de elegir entre deseos igualmente arbitrarios por lo que habíamos intentado construir una moralidad de la razón (...) La raíz del problema es la separación hecha por la doctrina liberal entre comprensión y valoración» (ibíd., págs. 54-55).

En suma, si huimos de la particularidad caemos en una universalidad vacía de principios abstractos, y si huimos de éstos, entonces volvemos de nuevo a una subjetividad particularista. Thiebaut muestra la analogía entre este dilema y el señalado por la crítica comunitarista, según la cual el pensamiento liberal o bien expresa unos valores particulares de una comunidad específica, que no serían válidos en otra, o bien esos principios son abstractos y no pertenecen a ninguna de ellas, con lo que no serían tampoco válidas en ambas.

La solución liberal suele ser presentada por los comunitaristas -pasando más bien al terreno de la filosofía política- como la distinción entre lo bueno y lo correcto, distinción que ellos impugnan, al igual que muchos CLS. La idea, bien conocida, sería la de que el liberalismo sostiene la tesis de la subjetividad, individualidad, arbitrariedad, etc., en el ámbito de la definición de «lo bueno», por lo que para hacer posible la coexistencia entre individuos con valores y planes de vida racionalmente inconmensurables habrá que acudir a reglas universales y racionales sobre «lo justo» o «correcto», que proporcionen procedimientos neutrales para dirimir las disputas sobre el bien. Aquí muchos miembros de CLS (yo creo que también Unger) incurren en un primer error de bulto -por lo demás bastante frecuente- al atribuir al liberalismo en su conjunto el «privilegio» de la idea digamos «emotivista» de que no se puede justificar la preferencia de unos valores sustantivos sobre otros. En esto por supuesto los liberales discrepan, mientras que lo que les uniría sería más bien la renuncia a la imposición pública de una determinada concepción del bien: aunque se piense que hay planes de vida objetivamente mejores, el Estado debe ser neutral por respeto a la autonomía, o por motivos epistémicos (cada uno es prima facie quien mejor puede conocer su propio bien), entre otras razones. Otros «CLSers» -por ejemplo, Kelman- son conscientes de este crucial «matiz», pero en todo caso critican lo que para ellos sería una artificial distinción 
entre lo correcto universal y lo bueno subjetivo y arbitrario (a fin de cuentas, aunque filosóficamente muchos liberales no sostengan esto último, en el terreno político y jurídico -que es el que a CLS más interesa- el efecto de su compromiso con la neutralidad estatal les llevaría a actuar «como si» lo sostuvieran). Esta crítica, que se conecta con la abundante literatura en CLS contra la distinción entre lo público (ámbito objetivo de lo correcto) y lo privado (ámbito subjetivo de lo bueno), siempre tiende en el fondo hacia un tema común con el de los comunitaristas: la imposibilidad de definir lo justo como algo anterior al bien sustantivo; éste se introduce siempre en la definición misma de las supuestas reglas formales universales; y en todo caso, como apuntaba la aporía de Unger, la opción sustantiva que se intentaba eludir se introduce necesariamente en el momento de la aplicación de las reglas formales a problemas reales (o de lo contrario permanecerían puras pero vacías e inaplicables). La solución de los comunitaristas sería la de dar prioridad a una concepción colectiva pero no universal del bien como juez de las preferencias individuales. Pero CLS (en su mayoría) tampoco aceptará esto. Veamos por qué.

\section{El rechazo de CLS a la solución comunitarista}

CLS no aceptaría la propuesta constructiva de los comunitaristas. Si, como he dicho, el grueso de CLS en realidad -pese a sus abundantes alusiones críticas- no ha entablado un debate serio con la filosofía ética liberal, mucho menos lo ha hecho con el comunitarismo. Pese a ello puedo imaginar, no sin riesgo, que es lo que dirían. Dividiré esta parte, a su vez, en tres puntos: el rechazo de CLS a la noción de los valores compartidos; la crítica a las contradicciones en el comunitarismo; y la crítica al comunitarismo como reconstrucción teórica.

2.1. El rechazo a los valores compartidos.-Por un lado, en general CLS rechazaría la idea de la comunidad (de las diferentes comunidades) como fuente suprema de la moralidad, ya que desde su visión fuertemente conflictualista ellos niegan una y otra vez la noción de los «valores sociales compartidos». Esto iría desde luego contra las visiones liberales «funcionalistas» que enfatizan el consenso como agregado resultante -mediante procedimientos neutrales- de preferencias genuinamente individuales. En esta crítica, frente a ese falso consenso los CLS suelen oponer la existencia de jerarquías ilegítimas sobre todo entre colectivos de clase, raza o sexo, por lo cual podrían parecer comunitaristas. Pero esto no es así, ya que tam- 
bién rechazan la creencia comunitarista en un «bien común» surgido del «mundo de la vida» de cada comunidad. Ya he señalado la ambivalencia de CLS respecto de la teoría descriptiva de la personalidad, a la que me remito. Y, desde un punto de vista normativo, la «contradicción fundamental» entre el yo y los otros se vive como «dolorosa» precisamente porque, por un lado, queremos «fundirnos» con los demás, y en especial con quienes nos rodean de manera más cercana, en una «existencia colectiva inalienada» (es decir, se reconoce el valor positivo de la comunidad), pero, por otro lado, esa fusión comunitaria amenaza con aniquilar nuestra libertad individual, que se quiere preservar a toda costa. Yo creo que, en esta dialéctica, el valor de la subjetividad y de la libertad individual acaba prevaleciendo en CLS, porque el valor otorgado por ellos a la comunidad se concibe: $\left.1 .^{\circ}\right)$ sólo en la medida en que ésta es necesaria para nuestra realización como individuos (ya que, a veces -no siempre-, nuestro bien efectivamente se funde con el de los demás); y 2..$^{\circ}$ ) con el límite de evitar esa aniquilación del individuo por el grupo. De manera que, en cuanto a cuáles son los valores que hay que defender, CLS en el fondo estaría con los liberales, aunque rechaza los esfuerzos de éstos por su fundamentación a través de una teoría ética. Un liberal crítico con CLS, Andrew Altman, en un libro que se titula precisamente CLS. Una crítica liberal, les defiende sin embargo de ataques, como el de William Ewald, que acusan a CLS de totalitarismo, de rechazar las libertades individuales asociadas a la filosofía política liberal:

«Yo no creo -dice Altman- que un examen justo de la literatura CLS pueda apoyar tal interpretación. Es, en el mejor de los casos, una grosera caricatura. Muchos autores de CLS efectivamente argumentan a menudo que los valores liberales presentan solamente un lado del relato humano, que hay cosas que la gente hace y debería celebrar y que son omitidos o distorsionados en la imagen liberal. La solidaridad y la comunidad son los valores más frecuentemente invocados a este respecto. Sin embargo, es un error inferir algún tipo de tendencia totalitaria en CLS a partir de su discurso de solidaridad, comunidad, etc. Sus autores están fuertemente comprometidos con las libertades individuales esenciales que los liberales han luchado por asegurar contra sus enemigos absolutistas, fascistas y totalitarios» ${ }^{14}$.

${ }^{14}$ Altman, Andrew, Critical Legal Studies. A Liberal Critique, Princeton University Press, Princeton, NJ, 1990, págs. 16-17. 
Altman documenta su afirmación con citas como las siguientes:

«Muchos pensadores liberales fueron devotos de la libertad. Aunque no fuera más que por esta devoción, contarán para siempre como héroes y maestros de la raza humana, y todos los pecados de Inglaterra serán perdonados por sus servicios a la libertad» [Unger, cit., pág. 277]; «Igual que la tradición republicanista enfatiza correctamente nuestra dependencia mutua, la tradición liberal enfatiza correctamente nuestra individualidad y las amenazas que representamos unos para otros» [Tushnet, Red, White and Blue, pág. 23]. «Incorporada a la noción de derechos hay un logro liberador de nuestra cultura: la afirmación de la libre subjetividad humana frente a las ataduras de la vida de grupo, junto a la paradójica contravisión de una vida de grupo que crea y nutre individuos capaces de libertad» [Duncan Kennedy, «Critical Labor Law Theory: A Comment», 4 Industrial Relations Law, Journal 506 (1981)].

2.2. Las contradicciones en el comunitarismo.-Otra línea de crítica de CLS al comunitarismo sería, cómo no, la de buscar también ahí sus contradicciones internas. Si el pensamiento liberal no puede prescindir de elementos comunitarios, el comunitarismo también "padecería» la presencia de elementos universalistas. Carlos Thiebaut no es evidentemente un «CLSer», pero CLS seguramente suscribiría estas palabras suyas sobre el comunitarismo:

«...si bien, y por una parte, muchos [comunitaristas] acordarían que las teorías racionalistas modernas de corte kantiano no llegan a dar cuenta cabal del entramado concreto de nuestra vida moral y de sus conflictos, algunos de entre ellos (...) no dudarían en señalar que en esa vida moral hay elementos universalistas que están ligados a nuestras nociones de autonomía y de justicia como los que se pretendían definir en el programa moderno de forma racionalista a la hora de establecer un punto de vista moral diferenciado de las moralidades concretas (...). [Refiriéndose a este comunitarismo, Thiebaut añade más adelante:] «otras posiciones -quizá más neohegelianas o neo-jovenhegelianas, como la de Taylor y la de Walzer- se inclinarán más bien por reivindicar el contenido normativo de la misma tradición moderna: lo que hemos de dejar de lado no son los ideales morales universalistas de esa tradición, sino una ya simplificada autocomprensión de la filosofía moral moderna. No habría que rechazar, por lo tanto, 
el universalismo ético moderno, sino comprenderlo como una perspectiva adquirida históricamente desde la que podemos pensar lo moral, no como su fundamento transhistórico» (...) «las propuestas políticas comunitaristas no pueden ejercitarse, como Walzer ha argumentado, si no es a partir del marco político del liberalismo y, en cierto sentido, como su complemento. De forma similar, y por lo que a la idea de comunidad respecta, no puede entenderse una idea homogénea de comunidad moral si no es a partir de una ya inevitable diferenciación que exige nociones de respeto a las diferencias y a las minorías, es decir, que requiere las nociones modernas de tolerancia y de dionidad del individuo. Así, la ambigüedad de las propuestas neoaristotélicas expresa también la ambigüedad que existe en la misma noción moderna y reflexiva de modernidad» ${ }^{15}$.

2.3. La crítica al comunitarismo como reconstrucción teórica.-En suma -y éste es quizá el punto principal de mi exposición-, lo que explica la postura de CLS frente al comunitarismo es sobre todo esto: CLS lo rechaza en cuanto un esfuerzo más por reconstruir una teoría filosófica normativa que fundamente la moral. La clave, pues, para entender la relación entre comunitarismo y CLS hay que buscarla en la actitud de CLS acerca de la teorización ética. Pero, dado que ese rechazo a la teorización ética, al igual que el punto anterior acerca de las contradicciones internas del comunitarismo, son críticas dirigidas también contra el liberalismo, será mejor abordar ambas cuestiones referidas conjuntamente a liberalismo y comunitarismo. Para ello abriré un último apartado en el que intentaré aclarar mejor la posición de CLS.

\section{El sentido de la contradicción y la actitud de CLS ante la teoría}

Volvamos al catálogo de las contradicciones (deontologismo/ consecuencialismo, justicia formal/justicia sustantiva, subjetivismo/objetivismo, individualismo/altruismo, intencionalismo/determinismo... y, quizá también, universalismo/comunitarismo). En su famoso artículo «Forma y sustancia en la adjudicación en Derecho privado», Duncan Kennedy conecta muchas de estas contradicciones liberales

15 Thiebaut, Carlos, «Neoaristotelismos contemporáneos», en Victoria Camps, Osvaldo Guariglia y Fernando Salmerón (eds.), Concepciones de la ética, Vol. 2 de la Enciclopedia Iberoamericana de Filosofia, Trotta / CSIC / Quinto Centenario, Madrid, 1992. en págs. 39, 43 y 46. 
con un conflicto sustantivo de nivel superior: el conflicto entre individualismo y altruismo. A ese gran conflicto él reconduce fundamentalmente la dicotomía entre la forma de reglas o de estándares en el Derecho (de eso se ocupa centralmente su artículo), pero también dicotomías político-morales como autodeterminación vs. paternalismo, regulación vs. facilitación, y, explícitamente, la que opone «comunidad vs. autonomía». Su tesis es que, en la actualidad, el conflicto entre individualismo y altruismo se encuentra en una situación de bloqueo: en todos los campos argumentativos (moral, económico, político y jurídico) ambas posturas, que en otros momentos históricos parecían más nítidas, se hacen importantes concesiones mutuas, se aproximan en posiciones pragmáticas o «razonables» que admiten elementos fundamentales de la tendencia opuesta, sin que una logre derrotar definitivamente a la otra. Esto se explica, según Kennedy, porque el conflicto constante entre individualismo y altruismo en el nivel «práctico y moral» no es sino el reflejo de una contradicción situada en un nivel todavía más profundo: el conflicto de fondo tiene lugar en un nivel «teorético», entre dos conjuntos de premisas opuestas acerca del carácter de la humanidad y la sociedad.

«La importancia de añadir esta dimensión teorética a la dimensión práctica y moral es que nos proporciona una nueva forma de entender el conflicto entre individualismo y altruismo. En particular, nos ayuda a explicar lo que antes llamé "puntos de estancamiento" en ambos lados: los momentos en que el individualista, en su movimiento hacia el estado de naturaleza, de repente se echa atrás y se convierte en altruista; y el momento simétrico en que el altruista se convierte en defensor de las reglas y de la autoconfianza en lugar de deslizarse hasta el final hacia el colectivismo o el anarquismo» (cit., nota 4, en pág. 1767).

Kennedy analiza cuáles son esas premisas (a las que llama «liberales» y «organicistas») que subyacen respectivamente al individualismo y al altruismo, y que en mi opinión recuerdan bastante al estudio de Unger de los principios del «liberalismo» y los de la posible alternativa de los «fines compartidos» (o sea, la comunitarista). «El individualismo está asociado -dice Kennedy (loc. cit.) al cuerpo de pensamiento acerca del hombre y la sociedad que a menudo se describe de forma muy general como el liberalismo». Aquí las dos premisas fundamentales son la de la subjetividad y arbitrariedad de los valores (definidas de forma casi idéntica a como lo hacía Unger) y la del carácter meramente instrumental de los grupos (y del Estado) respecto de los fines preexistentes de sus individuos: los grupos no 
son fines en sí mismos, no definen nociones del bien. Ambas premisas fundamentarían un orden social y jurídico individualista bajo un régimen de reglas que definen para cada individuo determinadas esferas de discrecionalidad arbitraria para la persecución de sus propios fines pudiendo ignorar a los demás (en Derecho privado, el Derecho de propiedad), y que regulan la interacción entre los individuos fuera de esas esferas de arbitrariedad (Derecho de contratos) de manera que puedan cooperar en áreas de la producción y el consumo para alcanzar cada uno, en la medida de lo posible, sus propios fines, sin necesidad de llegar a un acuerdo sobre los mismos o establecer ningún tipo de (imposible) consenso valorativo o interdependencia como seres morales. El juez se limitaría a aplicar estas reglas, «cuyos predicados son siempre hechos y nunca valores» (cit., pág. 1.770), y que por tanto posibilitan la certeza y la objetividad. La pasividad judicial «significa la renuncia del grupo a utilizar al Estado para imponer su visión del deber altruista frente a las visiones en conflicto de los individuos que persiguen su autointerés» (cit., pág. 1.771).

El altruismo, en cambio, partiría de premisas «organicistas» que son el reverso de las anteriores. Niega la arbitrariedad de los valores: nuestros fines y propósitos, y los de los demás, «están siempre en un estado de evolución, progreso o retroceso, en términos de un ideal universal de hermandad humana» (págs. 1.771-1.772). (Para nuestro análisis, por supuesto, tendríamos que sustituir lo de ideal universal de hermandad humana por ideal comunitario de hermandad en el grupo). «No controlamos totalmente -continua Kennedy en su exposición del modelo altruista- nuestro propio desarrollo moral (...), pero participamos en él más que simplemente lo experimentamos. De ahí que podamos hablar con sentido acerca de valores, y que quizás incluso sea ésta la forma más elevada de discurso» (pág. 1.772). El altruismo también niega la subjetividad de los valores: para el altruista, «la función de utilidad de A no es sólo dependiente de la de B, sino que no se puede distinguir verdaderamente de ella. Es cierto que sufrimos por el sufrimiento de otros; más importante aún, sufrimos directamente el sufrimiento de otros» (ibíd.). Por último, el altruista niega que el Estado sea sólo un instrumento para los fines preexistentes de los ciudadanos: «los fines son colectivos, y están en un proceso de desarrollo. De ahí que los propósitos que forman la base para la decisión moral sean los del hombre en sociedad, más que los de los individuos» (ibíd.). Partiendo de estas premisas, «el contra-programa utópico de la justicia altruista es el del colectivismo» (pág. 1.771). Afirma que la justicia consiste en un orden según fines compartidos, ya que «podemos alcanzar una comprensión de los valores que la gente ha entretejido en sus relaciones particulares 
y de la tendencia moral de sus actos» (pág. 1.773). «El Estado, y con él el juez, están destinados a desaparecer a medida que la gente llegue a sentir su común hermandad». Mientras tanto, reconociendo que la fuerza es todavía necesaria, «la aplicación directa de normas morales a través de estándares judiciales es preferible a un régimen de reglas basado en el agnosticismo moral» (pág. 1.771).

Hasta aquí la descripción de los modelos individualista y altruista. La tesis central de Kennedy es que esos puntos de estancamiento, esa paradójica situación de bloqueo surgida del compromiso y la simultánea persistencia del individualismo y del altruismo modernos, se debe al hecho de que «ambos [individualismo y altruismo] creen firmemente en ambos conjuntos de premisas, a pesar de que son radicalmente contradictorias» (pág. 1.774). El problema no es simplemente que en este nivel más profundo sus respectivas premisas subyacentes sean visiones del universo «radicalmente contradictorias». El problema es que «afortunada o desafortunadamente, la contradicción es tanto interna como externa, ya que hay muy pocos participantes en la cultura jurídica actual que sean capaces de eludir la sensación de estar creyendo en ambos lados simultáneamente» (pág. 1.776):

«La crítica altruista contra el liberalismo -dice Kennedy le suena a verdad al individualista que ya no cree en la posibilidad de generar conceptos que a su vez generarán reglas que definan un orden social justo. La crítica liberal contra la anarquía o el colectivismo le suena a verdad al altruista, que reconoce que después de todo no hemos superado la dicotomía fundamental entre el sujeto y el objeto. En la medida en que los demás son, hasta cierto punto, seres independientes e incognoscibles, el eslogan de los valores compartidos conlleva la amenaza real de una tiranía más opresiva aún que la alienación en un Estado liberal que sea al menos de algún modo altruista» (pág. 1774).

Las anteriores palabras permiten conectar esta contradicción «tanto interna como externa» entre las premisas del individualismo y el altruismo con el concepto de «la contradicción fundamental» que ya hemos visto y que Kennedy introdujo tres años después. En cualquier caso, sea en términos de una única «contradicción fundamental»o en términos de dos conjuntos de premisas contradictorias en un nivel «teorético» profundo, la conclusión de Kennedy es que «es inútil imaginar que el conflicto en el nivel moral y práctico [entre individualismo y altruismo] cederá ante un análisis en términos de conceptos de nivel superior. El significado de la contradicción en el 
nivel de la abstracción es que no hay un metasistema que, con tal de que pudiéramos encontrarlo, nos permitiría sintonizar con uno u otro modelo según lo "requieran" las circunstancias» (pág. 1.775). Cada modelo, no se olvide, incluye las premisas metaéticas opuestas.

A la luz de este análisis, ¿Cuál es la teoría ética de CLS? Ninguna. CLS es un movimiento de juristas que, desde luego, no ha construido ni ha pretendido construir por sí mismo una teoría ética original, propia del movimiento (la teoría de los «grupos orgánicos» propuesta por Unger puede considerarse como una reconstrucción ética no carente de cierta originalidad, pero no ha sido acogida por el resto del movimiento). CLS tampoco ha adoptado en común una sola teoría ya existente, tomándola prestada de los filósofos. Pudiera entonces pensarse que, en cuanto movimiento político, intelectualmente tan plural, si los CLS no comparten una misma teoría ética, al menos individualmente cada uno habrá adoptado alguna, aunque sea distinta de la de otros compañeros de movimiento. Ante esto la respuesta ha de ser más matizada. Es cierto que algunos miembros de CLS se manifiestan más o menos próximos a alguna filosofía ética (dado ese pluralismo interno, no falta incluso quien abraza una ética liberal de signo kantiano) ${ }^{16}$. Pero, por lo general, los CLS (o su mayoría, o su «centro de gravedad») suelen rechazar la posibilidad de fundamentar una teoría ética elaborada. Entonces, ¿ese rechazo está fundamentado en alguna teoría metaética?

${ }^{16}$ Estoy pensando (y quizá no sea el único) en Robert Gordon, miembro destacado de CLS, quien «sin embargo», en un artículo que lleva el significativo título de «Too Much Kant is Not the Problem» (Perspective, Vol. VIII, N. ${ }^{\circ}$ 8, October 1991, págs. 5 y 12), escribe: «Estoy dispuesto a afirmar, perfectamente consciente de su insuficiencia, pero absolutamente convencido de su necesidad como punto de partida, que todos nosotros (...) deberíamos darnos a cada uno el mayor espacio posible en nuestras búsquedas de la vida buena. Ésta es una imagen incompleta pero todavía sustancial de lo bueno para un individuo: incompleta porque está claro que yo no puedo saber qué es la vida buena desde esta visión pero sustancial porque especifica un respeto absoluto al individuo $\mathrm{y}$, si se concibe ampliamente, también exige unos mínimos, estándares de vida para todos. Hay muy pocos bienes sin comida en la mesa y un tejado sobre la cabeza. Es una visión abierta a infinitas interpretaciones, pero cerrada a la manipulación total». Más adelante, Gordon opone «esta visión esencialmente liberal», «que deja espacio para tantas formas de vida diferentes», a la «visión neo-nietzscheana que sostienen los multiculturalistas radicales» y «tanta gente de moda en la izquierda y la derecha hoy en día»: «Los "izquierdistas culturales" y los "multiculturalistas radicales" (...) no quieren una parte de la cultura occidental. Ellos argumentan que su racismo y su sexismo son esenciales a ella -perdiéndose de vista las cuestiones de clase en una izquierda cultural que frunce el ceño ante la sociología "positivista", y que Occidente es por tanto irredimiblemente malvado. Por eso exigen que cada grupo oprimido cree su propia literatura y filosofía. Pero -añade Gordon- es difícil imaginar cómo ellos o cualquiera puede hacer esta crítica sin invocar valores liberales como la igualdad y la libertad. Precisamente por- 
Explícitamente, los CLS tampoco han desarrollado con detalle una teoría metaética que explique su escepticismo teórico. Pero si, pese a ello, tuviera que dar cuenta al menos de su posición, yo diría que es algo así como la de un «agnosticismo metaético», un fuerte escepticismo no ya hacia los valores, sino hacia la teoría ética. Will Kymlicka (cit., nota 10, pág. 8) traza en este sentido la siguiente distinción:

«1) Alguna gente cree que los valores morales no existen realmente, y de ahí que nuestras "creencias" acerca de estos valores en realidad son sólo afirmaciones de preferencias personales. Como tales no pueden ser correctas o equivocadas, y no hay espacio para evaluarlas racionalmente. 2) Otros creen que aunque las creencias morales pueden ser correctas o incorrectas, no hay manera de organizarlas en principios sistemáticos. Nuestros juicios de valor proceden de una comprensión tácita o sentido de adecuación [appropriateness] que nos dice cómo responder a circunstancias particulares. Cualquier intento de formalizar estos juicios en reglas o principios abstractos los distorsiona y produce fórmulas vacías. 3) Todavía otros creen que aunque tenemos razones para nuestras creencias sobre la justicia, y aunque estas razones pueden ser organizadas en principios sistemáticos, los únicos tipos inteligibles de razones y principios son aquellos que apelan a nuestras tradiciones históricas. La justicia es una cuestión de interpretación cultural más que de argumentación filosófica».

Parece claro que la primera de las tres posturas esbozadas aquí por Kymlicka es la del emotivismo puro y duro, y que la tercera viene a ser la del comunitarismo. Yo creo que CLS no estaría en ninguna de ellas, sino más bien en la segunda. La contradicción señalada por Kennedy en«Form and Substance» se daría en el nivel de las premisas metaéticas, no ya en el de los juicios normativos, sobre los que perfectamente puede ocurrir que coincidamos y que los creamos

que su principio básico es la reciprocidad de derechos y obligaciones, el liberalismo no sólo proporciona una base para que los débiles puedan exigir igualdad con los fuertes; proporciona un fundamento en base al cual los fuertes deben escuchar (...). En su mejor versión, las insurgencias radicales siguen siendo precisamente este intento de afirmación de una comunidad de iguales. Pero cuando así lo hacen, y a medida que lo hacen, es en el nombre mismo de una sociedad libre e igualitaria. Lo demás es alguna forma de tribalismo».

Quien haya tomado en serio mi insistencia en la pluralidad interna de CLS, no debería sorprenderse de que estas palabras hayan sido escritas por alguien que sigue cómodamente situado en este movimiento, aunque apunten contra la generación de «postmodernos», feministas radicales y «multiculturalistas» que vienen protagonizando la vida de CLS en los últimos años. 
correctos. Dicho más claramente: un emotivista afirma positivamente la imposibilidad de preferir racionalmente entre valores sustantivos; sería un ateo. Creo que el mensaje de Kennedy es distinto: acerca de la opción misma entre emotivismo y racionalismo metaéticos, o entre subjetivismo y objetivismo de los valores, Kennedy suspendería el juicio; sería un agnóstico. Afirmaría que quizá existan valores objetivamente mejores y peores, pero:

«El único tipo de imagen que expresa el proceso mediante el cual actuamos, y actuamos, y actuamos, en una dirección, y luego llegamos al punto de estancamiento, es el de la filosofía existencialista: adoptamos compromisos, y los perseguimos. El momento del abandono no es más racional que el del comienzo, y es por igual un momento de terror» (cit., pág. 1.775).

Desde esta actitud ante la teoría ética, el sentido de las contradicciones del liberalismo se puede sintetizar así: CLS (o cierto CLS) parece reprochar al liberalismo esas contradicciones, pero no aspira a superarlas optando ellos claramente por uno de los términos en cada caso, ya que abrazar hasta el final solo uno de los polos llevaría a posturas probablemente coherentes, pero insostenibles. Por ejemplo: nadie es hoy un kantiano de los de «hágase justicia aunque perezca el mundo», ni tampoco un utilitarista de los de todo vale con tal de maximizar el placer. De hecho, creo que casi todos, por no decir todos, optamos por alguna postura intermedia, o por una tendencia hacia uno de los polos de la dicotomía kantismo/utilitarismo, pero corregida por consideraciones tomadas del otro polo: un cierto kantismo pero no ciego ante consideraciones consecuencialistas, o un cierto utilitarismo pero con algunos frenos «de principios». Con el universalismo/comunitarismo quizá ocurra algo parecido. La tesis de CLS es sin embargo la de que las contradicciones serían racionalmente irresolubles. Esto no quiere decir que no debamos actuar, de hecho tomamos posiciones intermedias, tomamos «un poco de esto y un poco de lo otro», y hacemos bien. Lo que niegan es que podamos aspirar a justificar esas opciones intermedias mediante una teoría ética racional y coherente, ya que esa teoría estaría infestada de últimas premisas contradictorias. Por eso sostienen que podemos intentar defender nuestras opciones, pero para ello renuncian a la elaboración de teorías morales ${ }^{17}$.

${ }^{17}$ Andrei Marmor, cuando -muy incidentalmente- alude a la visión que él etiqueta como «no-teoría», parece referirse a un escepticismo hacia la teorización ética normativa muy similar al que yo estoy atribuyendo a CLS (y que Marmor atribuye a 
Es importante advertir que el propio «CLSer» es consciente de estar también él en esa situación. En realidad, CLS sólo estaría reprochando al liberalismo o bien 1) la falta de reconocimiento de esas tensiones, o bien, en su caso, 2) la creencia en que algún modo de equilibrio o término medio puede ser coherente y racionalmente justificado. Quiero decir algo de cada uno de esos reproches:

El primero, practicado con entusiasmo por CLS, me parece que puede resultar trivial: de una u otra forma, casi todos somos conscientes de las dificultades y aporías fundamentales del discurso ético (aunque CLS tiene razón al denunciar que en demasiados casos ese reconocimiento supuestamente «trivial» queda luego olvidado o escondido a la hora de «poner manos a la obra»). Quizá no estén diciendo nada distinto a la idea bien familiar de que en la argumentación práctica (y en la teórica, a mayor abundamiento) en el fondo siempre necesitamos partir de premisas o presupuestos «últimos» (ontológicos o epistemológicos) que no se pueden demostrar. Aquí pues, la utilidad de CLS es para nosotros muy limitada. Aunque quizá algunos de sus trabajos sí puedan coadyuvar a iluminar mejor, o desde otro foco, nuestra conciencia de los problemas. Por ejemplo, viendo la relación entre los términos de las dicotomías como una relación dialéctica, más que como un continuum entre dos polos. Norberto Bobbio distinguía a este respecto entre una dialéctica «fuerte» y otra «débil». En la fuerte, p.e. la de Hegel, hay un momento de síntesis superador del conflicto, mientras que en la débil los opuestos se remiten uno a otro sin fin, algo así como una eterna partida de pin-pon. Yo creo que la visión de CLS es la dialéctica débil. Imagen ésta que me parece que se ve reforzada en CLS por la irrupción del sector de los «deconstruccionistas» derridianos, obsesionados por jugar con las dicotomías mostrando cómo cada tér-

Thomas Nagel y a Bernard Williams). La «no-teoría»-explica Marmor- «no equivale necesariamente al escepticismo radical», sino que «abraza la idea de que los principios morales, incluso si sostenemos que son objetivos y verdaderos, no pueden ser comprendidos en un conjunto de principios coherentes, ya que las contradicciones entre ellos reflejan genuinas contradicciones inherentes a nuestras vidas morales, o implicadas por la naturaleza de nuestras vidas sociales, etc.» (Interpretation and Legal Theory, Clarendon, Oxford, 1992, págs. 62-63). Así pues, la tesis de CLS, en una versión más débil (que seguramente dejaría fuera a los más radicalmente «irracionalistas» del movimiento) no rechazaría necesariamente la posibilidad de argumentar «racionalmente» a favor de nuestras opciones morales, e incluso de desarrollar muy limitadas «teorías locales» para defenderlas. Lo que rechazaría es más bien la posibilidad de una teoría a la vez coherente (que respete los -según CLS- elevados estándares de coherencia exigidos por la teorización ética «normal») y de amplio alcance (que fundamentara el conjunto, o una porción significativamente amplia, de dichas opciones). Visto así, la discusión radicaría en la magnitud o ámbito de la teoría. 
mino de ellas se opone y a la vez necesita del otro para su propia definición (¿igual que el «yo» y «los otros» en la «contradicción fundamental»?), cómo uno de los términos aparece privilegiado, y cómo se puede invertir esa jerarquía con la intención de... con la intención de volverla a invertir, e invertirla una vez más, y otra vez, y otra...

En cuanto al segundo reproche, el de que no hay manera de teorizar coherentemente una opción intermedia o alguna solución de equilibrio, ya no me parece tan trivial, sino más bien una tesis fuerte; demasiado fuerte. Creo que aquí le ocurre a CLS algo parecido a lo que tanto se ha reprochado al realismo jurídico americano (es sólo una analogía): los realistas partirían en realidad de una noción demasiado exigente de certeza jurídica, y al no verla satisfecha, habrían reaccionado dando el bandazo de afirmar una versión exagerada de la indeterminación jurídica. Independientemente de que este reproche haga o no justicia con los realistas, la imagen podría reproducirse para con CLS en lo que estoy aquí tratando: quizá en el fondo lo que les pase es que parten de una concepción demasiado fuerte de la racionalidad y la coherencia en la teoría ética, y al detectar que las teorizaciones de opciones intermedias o equilibradas no alcanzan ese listón, acaban diciendo que sólo se puede optar, no teorizar. Es como si CLS hiciera suyos precisamente esos elevados estándares de coherencia que el tipo de teorización que ellos critican se exige a sí misma. Una cosa es criticar la ambición de esa «gran teoría» por prometer mucho más de lo que puede cumplir, y otra bien distinta es, basándose en ello, rechazar a priori la posibilidad de construir un discurso ético general desde parámetros menos exigentes y más flexibles, como intenta hacer buena parte de la teoría ética contemporánea. Yo pienso que, por ejemplo, la noción rawlsiana del «equilibrio reflexivo», la retórica del «balanceo», o las teorías actuales de la argumentación, incluso con sus frecuentes apelaciones a «nuestras intuiciones morales básicas», no es que sean precisamente reglas de matemática contable para que nuestras cuentas morales nos cuadren, pero me parece que algo ayudan a la hora de, si no demostrar, al menos reforzar teóricamente nuestras precarias opciones, y hacemos así más llevadera nuestra penosa y fundamentalmente contradictoria existencia.

\section{Algunas conclusiones provisionales}

Hasta aquí, mi exposición sobre las relaciones entre CLS y el comunitarismo. Me parece que la respuesta a la doble pregunta que formulaba al principio, la de cuál sería la actitud de CLS ante el comunitarismo, y qué puede aportar CLS al debate entre comunita- 
ristas y liberales, puede resumirse así: CLS ha compartido con los comunitaristas algunos rasgos fundamentales de la crítica al liberalismo, pero rechaza la teorización positiva de los comunitaristas debido al fuerte escepticismo teórico (no nihilismo valorativo) que caracteriza a CLS; ese escepticismo explica precisamente que su aportación al debate teórico entre liberales y comunitaristas sea muy escasa, aunque su crítica sí plantea (o al menos expresa de otra manera) algunas preguntas que deben ser afrontadas. Precisamente, para finalizar, quisiera recopilar muy brevemente algunos puntos o conclusiones que podrían servir para una posible discusión.

1. Acerca del debate sobre la constitución de la personalidad: ¿es defendible una postura clara, una tesis fuerte, bien sea la individualista-atomista o la de la construcción social del yo? Mi opinión es que no, y supongo que cualquiera estaría de acuerdo: es verdad que todos los que estamos aquí más o menos compartimos una misma cultura, educación, contexto social, y sin embargo discrepamos en muchas cuestiones normativas; y también es cierto que compartimos ciertos valores (aquí nadie es partidario de la quema de herejes), y que en ello ese contexto ha tenido que influir bastante. ¿Aporta algo CLS a esta cuestión? Yo creo que poco: si verdaderamente es casi trivial negar los extremos, CLS no parece de oran ayuda a la hora de decir algo más. Nos muestra el problema como una dialéctica sin superación posible, pero una teoría ética que nos diga cómo debemos actuar no puede quedarse en la negación de los extremos: debe partir de alguna concepción más o menos precisa acerca de la personalidad, dentro de ese continuum, e intentar argumentarla.

2. El anterior punto hace referencia al llamado individualismo ontológico. Pero ese tipo de individualismo es diferente del individualismo epistemológico y del ético. La diferencia crucial entre el liberalismo y el comunitarismo se halla precisamente en este tercer nivel, es decir, los liberales, a diferencia de los comunitaristas, son individualistas éticos. Ahora bien, por lo que se refiere a CLS, en el plano epistemológico serían no-individualistas, enfatizando la «construcción social» del conocimiento (aunque, por cierto, su postura se diferencia bastante radicalmente de las teorías del consenso racional tipo Habermas). Pero en el plano ético creo que su postura se decantaría en último término hacia el individualismo y, por tanto, coincidiría en lo básico con la tesis del liberalismo, que yo también comparto.

3. Una tercera cuestión es la de si la contraposición entre liberalismo y comunitarismo tiene carácter exhaustivo y excluyente. Los partidarios de CLS defienden aquí que la contraposición ni es exhaustiva (el utopismo de muchos de estos autores evoca -aunque 
tampoco aquí exista una teoría al respecto- un ideal de comunidad, pero de comunidad universal), ni tampoco excluyente (y de ahí su inclusión de la dicotomía universalismo/comunitarismo en el catálogo de las contradicciones que padecemos).

4. CLS tiene razón, en mi opinión, al pensar que una concepción ética no puede prescindir del todo de ninguno de estos dos polos. Pero lo que no parece tan justificado es pensar que, frente a este dilema, no cabe otra cosa que aceptar (o sea, ser consciente) de la «contradicción fundamental» que conduce inexorablemente a tomar «un poco de esto y un poco de lo otro», sin más criterio que un pragmatismo puro y duro. Frente a ello, mi opinión es que cabe -o, al menos, no hay por qué rechazar ad liminem- la posibilidad de encontrar algún tipo de mediación, aunque para ello no podamos valernos de razones definitivas. En realidad, es posible que la crítica de los CLS al racionalismo se deba -paradójicamente- a una concepción de la racionalidad excesivamente estrecha. 